\title{
Recycling of Electrical Insulators, by their Secondary Use, as Substitutes for Mineral Aggregates in Artificial Composites Based on Orthophthalic Polyester Resins
}

\author{
Bartosz Zegardło' \\ 1 Siedlce University of Natural Sciences and Humanities, Research Team of Quantitative Methods and Spatial \\ Management, ul. Konarskiego 2, 08-110, Siedlce, Poland \\ * Corresponding author's e-mail: bart.z@wp.pl
}

\begin{abstract}
This paper is a continuation of the research work on the reuse of worn-out electric insulators. The aim of this analysis was to check the possibility of using this waste matter in composites in which the bonding phase is made of orthophthalic polyester resins. In order to test the thesis, a transparent resin composite was designed, which contained the recycled aggregates from worn-out electrical insulators. Aggregate with a grain size of 1-2 mm was prepared from the elements obtained during the renovation works. Unsaturated orthophthalmic polyester resin was used as binder. The initiator - methyl ethyl ketone peroxide - was used to cure the resin. Aluminum cement was used as a fine filling phase. A synthetic stone was produced from the substrates prepared in this way, which was subjected to the basic tests carried out for concretes used in construction. The density of the composite, absorbability, and strength parameters such as flexural tensile strength and compressive strength were examined. The results showed that from the described components it is possible to obtain a resin composite which, apart from interesting aesthetics, meets the requirements for construction materials used in the building industry.
\end{abstract}

Keywords: electrical insulators, resin composites, ceramic waste, recycling, recycled aggregates.

\section{INTRODUCTION}

The current requirements of the European Union require that each manufactured product should have the processing and recycling technology that takes into account the principles of environmental protection [Parliament Directive, 2008]. As this issue is being implemented recently, it is important to develop a number of new technologies for the disposal of products which have not been subject to rational secondary management so far. Ceramic products are an example of such products. The term "ceramics" [Awgustinik, 1980] comes from the Greek word "keramos" - clay, and it is used to describe all the products that are made from this raw material [Kielski, 1980, Maksymiuk, 1997]. Clay [Węgrowski, Przeździecka, 1979], which is a clay sedimentary rock due to the variety of materials it contains, takes on a wide range of forms reflected in its various properties. Electrical insulators are classified as the products made of noble-white clay. Their production process consists of several stages: forming, pre-firing, proper firing, glazing, as a result of which the ceramic material receives its unusual features.

Ceramic electrical insulators are elements used in power engineering to support and insulate conductive elements [Dictionary of Terminology, 2003]. Insulators may have a full structure - they are then called full-fledged, they may also have an empty space inside - the so-called hollow space. Due to the place of application insulators are divided into linear, standing, supporting, captive, extraction, etc.

Despite the fact that insulation is the main function of electrical insulators [Zegardło, Ogrodnik, Woliński, 2016], it should be remembered that their additional function is to transmit the force created from hanging wires. 
Apart from transmitting the tension force, insulators must also transmit side loads such as additional load of wind, ice or cold. Therefore, the materials used in their production have very high strength parameters. These materials are insensitive to the weather conditions, high temperatures and chemically aggressive environments. Since electric insulators, as a product, are connected in systems with other elements, e.g. steel, they have a limited service life. Despite the technical possibilities of a very long period of failure-free operation of ceramic elements, it is estimated that the period of failurefree operation of these ceramic-steel systems is about 30 years. After this period of time, the worn out electric insulators are replaced with new ones during the repair works. According to market surveys and the information obtained from the companies disposing of electric insulators, the most frequently undertaken method of disposal is their use in the branches of transport construction [Ogrodnik, Zegardło, 2016, Ogrodnik et al. 2016] Due to the specificity of the place where the waste is used, the role and purpose of the disposal of the substances, two main criteria for the division of their applications are being used.

The first area that has been functioning on the industrial market for quite a long time is the so-called broadly defined land levelling. The construction, in particular, of linear communication facilities (roads, railways) requires the movement of large earth masses. It often happens that the mass balance for the planned section is negative. In such cases, the most convenient solution is to reach the local deposits of natural aggregates. However, if there are no such deposits or the parameters of the aggregates present in them do not meet the expected requirements, recycling aggregates are used. The most popular waste substance in this place is the so-called concrete destruction resulting from the crushing of concrete elements [Jamrozy, 2006]. It is also common to use worn-out, waste, building ceramic materials more and more often in these places. The talks with entrepreneurs have proven that nowadays, electric insulators received from electric companies are disposed of in industrial crushers. They are crushed and the steel elements are separated . The resulting aggregate is used to harden the surface of ground roads or as a foundation for concrete or paving stones.
Another direction of utilization, which is expected to be used on a large scale also in the transport construction industry, has emerged relatively recently on the wave of wide public interest in the subject of environmental safety. This is the socalled production of "green concretes", i.e. organic concrete [De Brito et al., 2005, Senthamarai et al., 2011, Halicka et al., 2014, Lopez et al., 2007, Senthamaraiet al., 2005]. It is not directly driven by the market needs, but is a search for a way to reduce the negative environmental impact of industry and construction. There are a few papers that address this issue and focus exclusively on the waste insulation ceramics.

In the paper [Senthamarai et al., 2005] the authors used crushed electrical ceramic insulators as a substitute for natural stone gravel. The concrete was prepared using portland cement, traditional stone aggregate with a grain size of up to $20 \mathrm{~mm}$, aggregate obtained from crushed electrical insulators (grain diameter of up to $20 \mathrm{~mm}$ ) and water. Stone aggregate was not combined with ceramic, but either stone or ceramic aggregate was used in two groups of mixtures. On the basis of the research, the authors found that the properties of the concretes made on the basis of the aggregate from crushed electrical insulators do not differ more than a few percent from those of the concretes made on the basis of traditional aggregates (except for modulus of elasticity). Depending on the type of prepared mix, the compressive strength was $1-3 \%$ lower or higher, while the modulus of elasticity for the mix on ceramic aggregate was 4 times higher, on average. On this basis, the authors found the suitability of the aggregate made of ceramic electric insulators for use in concrete mixes.

The effects of continuing research on the concrete based on the aggregates from electric ceramic insulators are presented in the paper [Senthamarai et al., 2011]. It focuses on the comparison of the concretes made with the aggregate from crushed ceramic insulators with concretes on navy blue aggregate in terms of: water absorption, pore volume and chloride diffusion, with a changing $\mathrm{w} / \mathrm{c}$ index. The results of the concrete density and strength tests showed that there are no clear differences between the concretes being compared, and that the above mentioned characteristics differ more with regard to the water-cement ratio than with regard to the type of aggregate used. 
The co-author's research work of the author of this article [Zegardło, et al., 2016] presents the results of concrete research, in which also the only aggregate used in the investigations were crushed electrical insulators. In these studies, high grade cement CEM I 42.5N - SR 3/NA and admixture - ISOFLEX 7130 superplasticizer were used to prepare the concrete. The purpose of using these components was to obtain high grade concrete composites. The presented results obtained from the tests of strength parameters of the recycling composites compared to traditional composites proved that waste electrical insulators can also be used in this way. The characteristics of the aggregates obtained from them met the requirements for aggregates for concrete, and the concretes made with their participation had the parameters allowing classifying them as special highstrength concretes. Attention was also drawn to the fact that these composites had higher strength parameters than those obtained with the use of special basalt aggregates, which are used especially for these purposes. This was proof that the aggregates from electrical insulators could replace not only traditional aggregates - gravel, but also special aggregates - for composing high-grade concrete.

The results of the research above prompted the author of this paper to check the possibility of using waste electrical insulators to produce synthetic composites prepared on the basis of orthophthalic polyester resins with their participation. In spite of the works on the utilization of insulators, there were no results of the studies in which insulators would appear as a substrate in resin composites. An additional aspect was the planned filling of the mixture with aluminum cement. These observations proved the novelty of the analyses undertaken and motivated the research described below.

\section{MATERIALS}

The basic raw material for the production of the synthetic composite involved the electric insulators obtained by an electrical company during the renovation works of overhead electrical lines. The waste obtained in this way was transported in containers to a landfill (Fig. 1). Afterwards, the waste in the presented form was transported to the laboratory, initially crushed

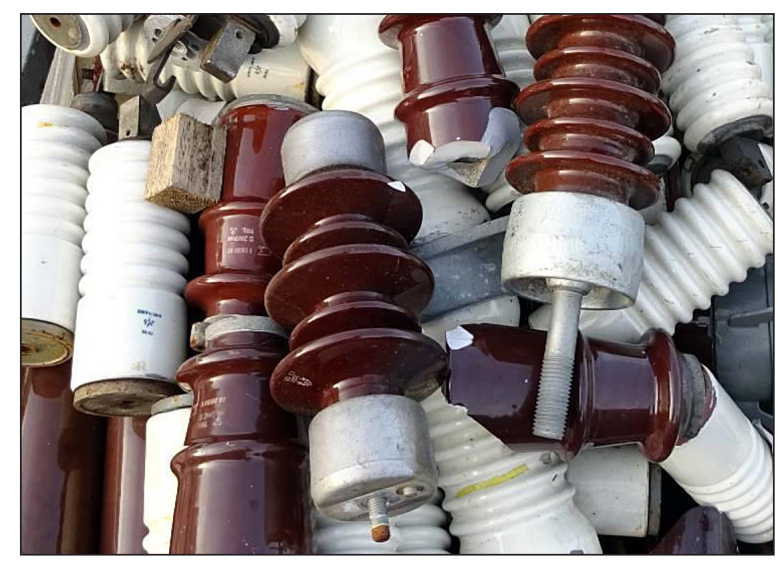

Figure 1. Disused electrical insulators in a landfill

and cleaned of steel elements. Then it was subjected to a proper crushing process using impact devices. The aggregate obtained in this way was subjected to the process of screening through 2 $\mathrm{mm}$ and $1 \mathrm{~mm}$ mesh screens. The aggregate obtained in this way is presented in Figure 2.

The condition for obtaining a composite material which is both decorative and characterized by high strength parameters required the use of a suitable binder. It was considered that the material should be a transparent resin, which remains transparent after curing and has high strength parameters. This goal was dictated by the desire to prepare a permanent composite, in which ceramic aggregate filling will be exposed. Taking into account the above factors, a colorless, transparent unsaturated Crystal Clear Synolite 1881 polyester resin made by Scott Bader Finland was used. The basic parameters of the resin from its technological chart are presented in Table 1.

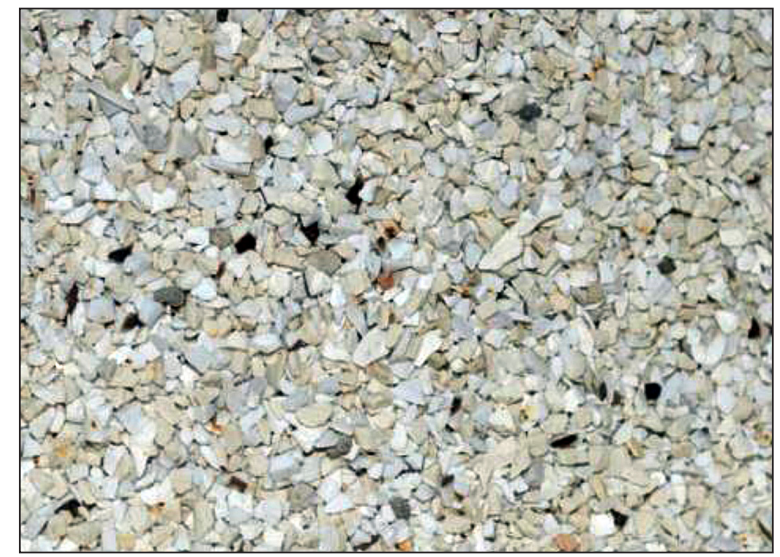

Figure 2. Aggregate grains from waste electrical insulators subjected to sieving through screens of 1 and $2 \mathrm{~mm}$ mesh size 
Table 1. Basic properties of Crystal

Clear Synolite resin

\begin{tabular}{|c|l|c|}
\hline No. & \multicolumn{1}{|c|}{ Feature } & Value \\
\hline 1 & Mixing ratio by weight & $100 \mathrm{~A}: 90 \mathrm{~B}$ \\
\hline 2 & Viscosity after mixing $(\mathrm{mPa} \cdot \mathrm{s})$ & 600 \\
\hline 3 & Specific gravity $\left(\mathrm{g} / \mathrm{cm}^{3}\right)$ & 1.04 \\
\hline 4 & Colour & clear \\
\hline 5 & Plastic preservation time & 20 minutes. \\
\hline 6 & Disassembly time & 16 hours \\
\hline 7 & Hardness (Shore $\mathrm{D})$ & 80 \\
\hline 8 & Breaking strength $\left(\mathrm{N} / \mathrm{mm}^{2}\right)$ & 17.2 \\
\hline 9 & Modulus of elasticity $\left(\mathrm{N} / \mathrm{mm}^{2}\right)$ & 504 \\
\hline 10 & Elongation at break $(\%)$ & 10 \\
\hline 11 & Bending strength $\left(\mathrm{N} / \mathrm{mm}^{2}\right)$ & 73.35 \\
\hline 12 & $\begin{array}{l}\text { Modulus of elasticity at } \\
\text { bending }\left(\mathrm{N} / \mathrm{mm}^{2}\right)\end{array}$ & 1377 \\
\hline 13 & Compressive strength $\left(\mathrm{N} / \mathrm{mm}^{2}\right)$ & 43.98 \\
\hline 14 & $($ N/mm2) & 275 \\
\hline 15 & Shrinkage $(\%)$ & 0.1 \\
\hline 16 & Heat resistance $\left({ }^{\circ} \mathrm{C}\right)$ & 50 \\
\hline 17 & Refractive index & 1.49962 at $20^{\circ} \mathrm{C}$ \\
\hline
\end{tabular}

For curing of the resin the initiator - methyl ethyl ketone peroxide Butanox M-60 - was used, according to the manufacturer's recommendation, in the amount of $3 \%$ by weight of the resin used. The basic initiator properties are presented in Table 2.

As an additional component of the composite, which was to fill the spaces between the grains of the recycling aggregate, the Górkal high alumina cement - class 70 - was used. This snow-white cement is recommended by the manufacturer for use in concretes and mortars which are exposed
Table 2. Basic properties of Butanox M-60 hardener

\begin{tabular}{|c|l|c|}
\hline No. & \multicolumn{1}{|c|}{ The property } & Value \\
\hline 1 & The character & Transparent liquid \\
\hline 2 & Density & $1170 \mathrm{~kg} / \mathrm{m} 3$ \\
\hline 3 & Viscosity & $25 \mathrm{mPa} . \mathrm{s}$ \\
\hline 4 & Solubility in water & Insoluble \\
\hline 5 & Solubility in flats & Soluble \\
\hline 6 & Auto-ignition temperature & $220^{\circ} \mathrm{C}$ \\
\hline 7 & Hazardous reactions & $\begin{array}{c}\text { Do not mix with } \\
\text { the accelerators }\end{array}$ \\
\hline 8 & Skin irritation & Corrosive \\
\hline 9 & Eye irritation & $\begin{array}{c}\text { Heavily irritating/ } \\
\text { corrosive }\end{array}$ \\
\hline 10 & Ames test & Not mutagenic \\
\hline
\end{tabular}

during operation to chemically aggressive environments and high temperatures. The main features of the cement are presented in Table 3.

Ultimately, the composition of the composite was designed using an experimental method consisting of iterative dosing of the binder to the connected fillers until all the components obtained a liquid consistency suitable for the mixture in molds. The final composition of the composite is presented in Table 4.

\section{METHODOLOGY}

The program of the planned research works assumed the assessment of the composite aesthetics and conducting the basic tests to which the construction materials used in industry are subjected. The specific density of the composite, absorbability and strength parameters such as

Table 3. Characteristics of the Gorkal 70 cement declared by the manufacturer

\begin{tabular}{|c|c|c|}
\hline Features & Declared performance & Method of testing \\
\hline Dry mix appearance & White powder & ------ \\
\hline Blaine specific surface area & $4000 \div 5000$ & N-EN 196-6:2011 \\
\hline Aluminium oxide (Al203) content. \% & $69 \div 71$ & N-EN 196-2:2006 \\
\hline Sulphide content (S2-). \% & $\leq 0.10$ & N-EN 196-2:2006 \\
\hline Chloride content (Cl -). \% & $\leq 0.10$ & N-EN 196-2:2006 \\
\hline Alkali content (Na20+0.658K20). \% & $\leq 0.50$ & N-EN 196-2:2006 \\
\hline Sulphuric acid anhydride (S03) content. \% & $\leq 0.50$ & N-EN 196-2:2006 \\
\hline Chromium. Cr (VI) content. \% & $\leq 0.0002$ & N-EN 196-10:2008 \\
\hline Specific density. g/cm3 & $2.96+/-10 \%$ & N-EN 196-6:2011 \\
\hline Beginning of the binding time. min. marking on the leaven & $\geq 90$ & N-EN 196-3+A1:2011 \\
\hline Start of setting time. min. marking on the standard mortar at $w / c=0.5$ & $\geq 75$ & PN-EN 480-2:2008 \\
\hline Compressive strength (pry w/c=0.5). MPa. after $6 \mathrm{~h}$ & $\geq 18$ & N-EN 196-1:2006 \\
\hline Compressive strength (pry w/c=0.5). MPa. after 24 hours & $\geq 30$ & N-EN 196-1:2006 \\
\hline Ordinary fire resistance. cone bending temperature. OC & $\geq 1560$ & NYPD 993-13:2002 \\
\hline
\end{tabular}


Table 4. Composition of synthetic composite material containing waste electrical insulators

\begin{tabular}{|c|l|c|c|c|c|}
\hline No. & \multicolumn{1}{|c|}{ Substrate } & Quantity in $\mathrm{kg} / \mathrm{m}^{3}$ & Density $\mathrm{kg} / \mathrm{m}^{3}$ & Volume in $\mathrm{dm}^{3}$ & Weight \\
\hline 1 & $\begin{array}{l}\text { Polyester resin Crystal } \\
\text { Clear Synolite 1881 }\end{array}$ & 614.7 & 1.1 & 286.09 & 27.50 \\
\hline 2 & Butanox initiator M-60 & 9.441 & 1.17 & 8.07 & 0.41 \\
\hline 3 & $\begin{array}{l}\text { Aggregate of electrical } \\
\text { insulators. 1-2 mm grit size }\end{array}$ & 966.4 & 2.63 & 481.52 & 42.50 \\
\hline 4 & Highlander cement 70 & 698.3 & 3.1 & 225.26 & 30.51 \\
\hline & Sum & 2288.841 & & 1000.94 & 100 \\
\hline
\end{tabular}

compressive and bending tensile strength, were examined.

The volumetric density was tested on rectangular samples of $4 \times 4 \times 16 \mathrm{~cm}$. Six samples of the composite tested were prepared. The samples were measured and weighed according to the guidelines of [EN 12390-7:2009]. Volumetric density was calculated as the ratio of the volume of the tested samples to their mass.

Water absorption was tested on the same samples as volumetric density. Six samples of composites were tested as well. The samples were immersed in water and remained in it to determine their mass. Absorbency was calculated according to [Neville, 2012] as the ratio of the amount of water the composite was able to absorb to the dry mass of the composite expressed as a percentage.

The bending tensile strength was tested according to [EN 12390-5:2005]. The largest diameter of the aggregate used was $2 \mathrm{~mm}$, so $4 \times 4 \times 16$ $\mathrm{cm}$ specimens were prepared for testing. The test was also carried out on 6 specimens.

The compressive strength test was carried out in accordance with [EN 12390-3:2006]. The test was carried out on $4 \times 4 \times 4 \mathrm{~cm}$ specimens formed after breaking the specimens during the bending strength test. The final value was obtained from 12 results.

\section{RESULTS}

The aesthetic evaluation of the product proved that both the binder and the fillers met the author's expectations. The resin was transparent. The ceramic filler grains were clearly visible despite mixing the binder with white cement filler. The liquid mixture is shown in Figure 3. A close-up of the product cast in a plastic form is shown in Figure 4.

The results of the research: volumetric density and absorbability are presented in Table 5 . The table above also presents the results of research taken from the works [Zegardło, et al., 2016] and [Ogrodnik, Zegardło, 2018] in which a team of authors examined the same characteristics for high quality cement concretes with traditional fillers, i.e. gravel and basalt as well as recycling fillers from electrical insulators and resin composites with river sand.

The results of the tests of resin composites both for fillers with recyclate from electrical insulators and sand were very similar. These values did not differ by more than $1 \%$. It was

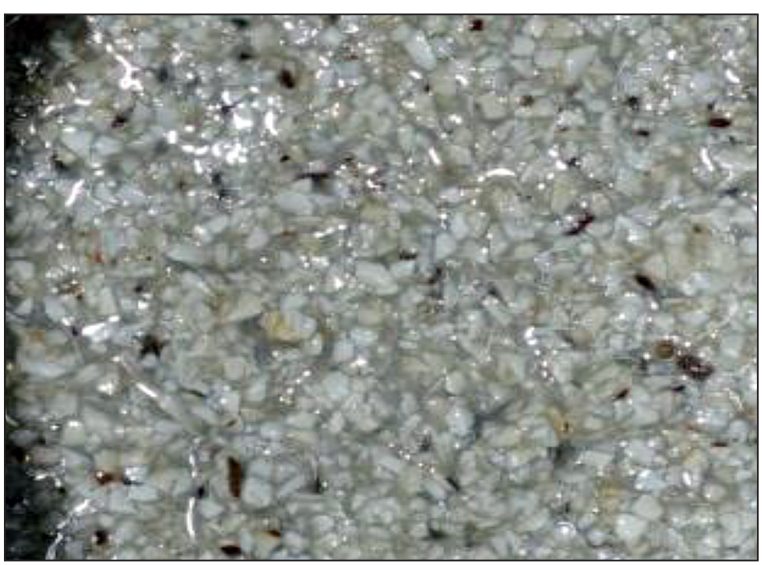

Figure 3. Liquid mixture

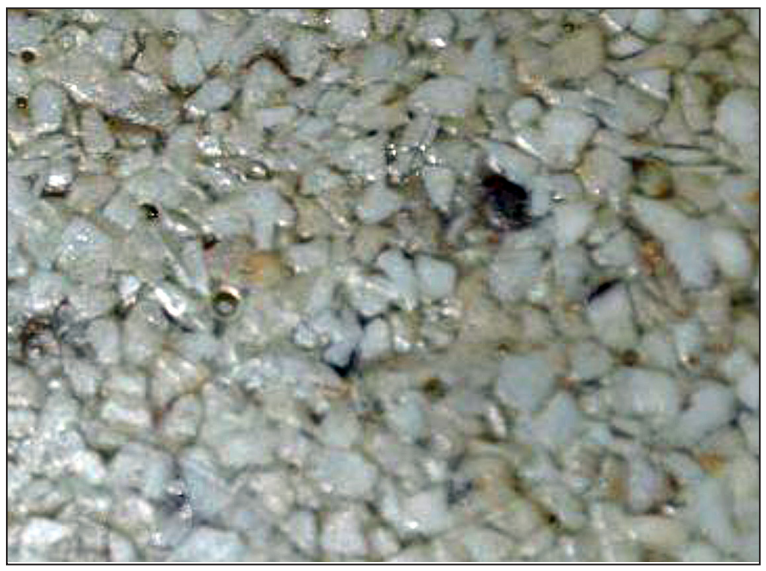

Figure 4. Proximity to the surface of a product cast in a plastic mould 
Table 5. Results of tests of synthetic composite against the results obtained for similar composites containing other components [Zegardło, et al., 2016, Ogrodnik, Zegardło, 2018]

\begin{tabular}{|l|c|c|c|c|}
\hline \multirow{2}{*}{ Parameter } & \multicolumn{4}{|c|}{ Composite type } \\
\cline { 2 - 5 } & $\begin{array}{c}\text { Resin composite } \\
\text { with recyclate from } \\
\text { electrical insulators }\end{array}$ & $\begin{array}{c}\text { Resin composite } \\
\text { with river sand }\end{array}$ & $\begin{array}{c}\text { Cement concrete } \\
\text { with basalt and } \\
\text { gravel aggregates }\end{array}$ & $\begin{array}{c}\text { Cement concrete with } \\
\text { ceramic aggregates }\end{array}$ \\
\hline Specific density & $2028 \mathrm{~kg} / \mathrm{m}^{3}$ & $2031 \mathrm{~kg} / \mathrm{m}^{3}$ & $2021 \mathrm{~kg} / \mathrm{m}^{3}$ & $1996 \mathrm{~kg} / \mathrm{m}^{3}$ \\
\hline Absorbency & $0.57 \%$ & $0.48 \%$ & $3.34 \%$ & $4.43 \%$ \\
\hline
\end{tabular}

Table 6. Strength parameters tested for resin composite with filler from electrical insulators and aluminum cement

\begin{tabular}{|c|c|c|c|c|}
\hline $\begin{array}{l}\text { Sample } \\
\text { number }\end{array}$ & $\begin{array}{l}\text { Strength of the i-th } \\
\text { sample, } \mathrm{MPa}\end{array}$ & Medium strength, $\mathrm{MPa}$ & $\begin{array}{c}\text { Standard } \\
\text { deviation, } \mathrm{MPa}\end{array}$ & Volatility rate, $\%$ \\
\hline \multicolumn{5}{|c|}{ Flexural tensile strength } \\
\hline 1 & 13.10 & \multirow{6}{*}{12.82} & \multirow{6}{*}{0.46} & \multirow{6}{*}{3.55} \\
\hline 2 & 12.40 & & & \\
\hline 3 & 12.80 & & & \\
\hline 4 & 12.60 & & & \\
\hline 5 & 13.90 & & & \\
\hline 6 & 12.10 & & & \\
\hline \multicolumn{5}{|c|}{ Compressive strength } \\
\hline 1 & 92.80 & \multirow{12}{*}{93.98} & \multirow{12}{*}{0.74} & \multirow{12}{*}{0.79} \\
\hline 2 & 93.60 & & & \\
\hline 3 & 94.40 & & & \\
\hline 4 & 95.70 & & & \\
\hline 5 & 92.40 & & & \\
\hline 6 & 93.50 & & & \\
\hline 7 & 94.30 & & & \\
\hline 8 & 93.20 & & & \\
\hline 9 & 94.10 & & & \\
\hline 10 & 93.90 & & & \\
\hline 11 & 95.40 & & & \\
\hline 12 & 94.40 & & & \\
\hline
\end{tabular}

probably caused by very similar parameters of ceramic material and sand and the same, identical form of fillers used (grains with diameter from 1 to $2 \mathrm{~mm}$ ). When comparing the results of the presented tests for resinous concretes to those for cement concretes, the differences in absorbability can be observed. Despite the fact that the density value was similar, resinous concretes had six-fold lower absorbability. These results were relatively easy to predict because this parameter is much more influenced by the quality of the binder used than the aggregate itself.

The results of strength tests are presented separately for the composite with a filler of electrical insulators (Table 6) and with the filler in the form of sand [Ogrodnik, Zegardło, 2018] (Table 7). A sample of the composite during the compressive strength test is shown in Figure 5.
The results obtained from the strength tests of the composite were satisfactory and allowed to classify it as useful for making structural elements. The parameters for the composite with filler from electrical insulators were definitely higher than for the composite with sand filler. Tensile strength was higher by $34 \%$ and compressive strength was about twice higher. The presented correlation of the results probably showed that fillers played a significant role in the composition of both composites. The sand filler has round grains which do not wedge between each other, as it was the case with composite with insulator aggregate. The clear tight arrangement of the recyclate grains visible in Figure 4 could significantly increase its technical parameters. Moreover, the fact that no additional filler with a smaller grain size was used in 


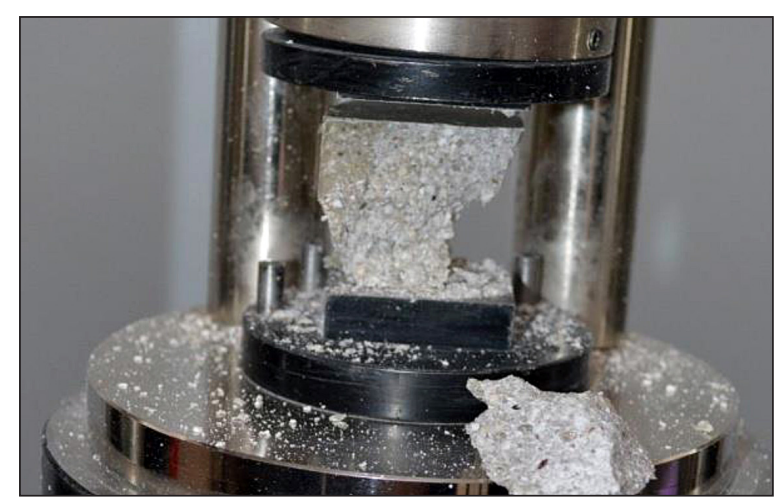

Figure 5. Composite sample during the compression strength test

the strip composite could cause that most of the stress was carried by the resin. Well-chosen proportions of fine and coarse (recycling) filler and its form of angular grains could cause the aggregate to form a tight load-bearing framework. The task of the binder was only in this case to bond the grains of this aggregate skeleton.
The results obtained from the tests of resin composites were also referred to the results from the strength tests for cement composites presented in [Ogrodnik, Zegardło, 2018] (Table 8).

The results of the tensile strength test of cement composites were significantly lower than those recorded for resin bonded composites. The value for a composite with recyclate from the insulators prepared on the basis of Portland cement was $7.20 \mathrm{MPa}$, while for a resin composite almost twice as much as $12.82 \mathrm{MPa}$. As it is known, cement binders do not allow obtaining composites with high tensile strength. As confirmed by the study, resin binders can be used in this case. Despite the use of the same type of filler, the value of this parameter increased significantly.

The compressive strength of the composite with recyclate made of insulators based on polyester resins was also higher, although only by $8 \%$, than that of the composite with cement binder. Here, the quality of the binder used did not play such a significant role as in the tensile strength.

Table 7. Strength parameters presented in [Ogrodnik, Zegardło, 2018] for a resin composite with sand filler

\begin{tabular}{|c|c|c|c|c|}
\hline Sample number & $\begin{array}{l}\text { Strength of the i-th } \\
\text { sample, } \mathrm{MPa}\end{array}$ & Medium strength, $\mathrm{MPa}$ & Standard deviation, $\mathrm{MPa}$ & Volatility rate, $\%$ \\
\hline \multicolumn{5}{|c|}{ Flexural tensile strength } \\
\hline 1 & 9.40 & \multirow{6}{*}{9.05} & \multirow{6}{*}{0.32} & \multirow{6}{*}{3.52} \\
\hline 2 & 9.35 & & & \\
\hline 3 & 9.20 & & & \\
\hline 4 & 8.90 & & & \\
\hline 5 & 9.22 & & & \\
\hline 6 & 8.25 & & & \\
\hline \multicolumn{5}{|c|}{ Compressive strength } \\
\hline 1 & 38.50 & \multirow{12}{*}{37.77} & \multirow{12}{*}{0.70} & \multirow{12}{*}{1.85} \\
\hline 2 & 35.90 & & & \\
\hline 3 & 36.70 & & & \\
\hline 4 & 39.40 & & & \\
\hline 5 & 37.50 & & & \\
\hline 6 & 38.00 & & & \\
\hline 7 & 37.50 & & & \\
\hline 8 & 38.20 & & & \\
\hline 9 & 37.90 & & & \\
\hline 10 & 37.40 & & & \\
\hline 11 & 38.80 & & & \\
\hline 12 & 37.40 & & & \\
\hline
\end{tabular}

Table 8. Results of the research on the cement composites presented in [Ogrodnik, Zegardło, 2018]

\begin{tabular}{|c|c|c|c|c|}
\hline Feature & Unit & $\begin{array}{c}\text { Aggregate concrete from } \\
\text { electrical insulators }\end{array}$ & $\begin{array}{c}\text { Cement concrete on } \\
\text { basalt aggregate }\end{array}$ & $\begin{array}{c}\text { Cement concrete on } \\
\text { traditional gravel aggregate }\end{array}$ \\
\hline Tensile strength & $\mathrm{MPa}$ & 7.20 & 6.70 & 4.30 \\
\hline Compressive strength & $\mathrm{MPa}$ & 86.40 & 76.50 & 49.90 \\
\hline
\end{tabular}


Referring to the results obtained for the concrete composites with other aggregates traditionally used in construction, it was noted that the presented composite has all technical parameters higher than the traditional composites. The compressive strength of the recycling composite was almost twice higher than that of traditional gravel composites and 18\% higher than that of high quality composites based on high quality basalt aggregates.

\section{CONCLUSIONS}

The market analyses have shown that after the period of about 30 years, overhead electrical lines need to be overhauled due to the need to replace electric insulators. This type of waste material is suitable for crushing and producing a substitute for natural aggregate from it. The research works presented in the article proved that crushed electrical insulators can be used to produce a synthetic composite. The composite, which consisted of electric insulators crushed to 1-2 mm grains, orthophthalic polyester resin, filler in the form of aluminum cement and resin hardener had unusual features and high technical parameters. The aesthetics of the manufactured composite resembled resin conglomerates, which are popularly used to make window sills and kitchen worktops. However, the technical parameters of the obtained composite were higher than those of cement composites used in the construction industry. The density, water absorption, tensile and compressive strength values were higher than those of traditional composites. Special attention was paid to the fact of high tensile strength, which was almost two times higher than that of cement concretes.

In view of the above, it is considered reasonable to use an aggregate made of electrical insulators for the manufacture of synthetic composites, with particular attention paid to the possibility of using them in structural elements, which should both have high tensile strength and unusual aesthetics.

\section{REFERENCES}

1. Awgustinik A.J. 1980. Ceramics. Arcades, Warsaw.

2. De Brito A., Pereira J., Correia R., Oliviera C. 2005. Mechanical behavior of non-structural concrete made with recycled ceramic aggregates. Cement and Concrete Composites, 27, 429-433.

3. Directive 2009/98/EC of the European Parliament and of the Council of 19 October 2008 on waste.
4. EN 12390-3:2006. Testing hardened concrete-Part 3: Compressive strength of test specimens.

5. EN 12390-5:2005. Testing hardened concrete-Part 5: Flexural strength of test specimens.

6. EN 12390-7:2009 Testing hardened concrete - Part 7: Density of hardened concrete.

7. German construction standard 1951-DIN 4163: Concrete with crushed bricks - Specification for production and use.

8. Halicka A., Ogrodnik P., Zegardło B. 2013. Using ceramic sanitary ware waste as concrete aggregate. Construction and Building Materials, 48, 295-305.

9. Jamrozy Z. 2006. Concrete and its technology. PWN, Warsaw.

10. Kielce A. 1980. General ceramic technology. Scripts of the Technical University of Koszalin, Koszalin.

11. Lopez V., Llamas B., Juan A., Moran J. 2007. Ecoefficient concretes: impact of the use of white ceramic powder on the mechanical properties of concrete. Biosystems Engineering, 96(4), 559-564.

12. Maksymiuk J. 1997. Electrical apparatus in questions and answers. WNT, Warsaw.

13. Neville A.M. 2012. Concrete properties. Polish Cement, Warsaw.

14. Neville A.M., 2012. Concrete properties, association of cement and cork producers. Warsaw.

15. Ogrodnik P., Zegardło B. 2016. Analysis of the possibility of using waste ceramic substances in building structures and transport engineering structures. TTS Technika Transportu Szynowego, 12, 1732-1738.

16. Ogrodnik P., Zegardło B. 2018 Use of waste ceramic materials and polyester resins for the manufacture of synthetic composites with structural concrete properties for use in construction, Chemical Industry, 97(1), 144-148.

17. PN-IEC 60050-151:2003 International dictionary of terminology for electrical installations - Part 151: Electrical and magnetic equipment.

18. Senthamarai R.M., Devadas M. 2005.Concrete with ceramic waste aggregate. Cement and Concrete Composites, 27, 910-913.

19. Senthamarai RM., Devadas M., Manoharan P., Gobinath D. 2011. Concrete made from ceramic industry waste: Durability properties. Construction and Building Materials, 25, 2413-2419.

20. Węgrowski W., Przezdziecka K. 1979. Glass and ceramics. State School Publishers, Warsaw.

21. Zegardło B., Ogrodnik P. Initial analysis of basic parameters of recycling of ceramic sanitary cullet in terms of its possible use for production of mineralasphalt mixtures. Buses, 12, 1715-1718.

22. Zegardło B., Ogrodnik P., Woliński P. 2016. An attempt to use waste electrical insulators as concrete aggregates - own research. Electrotechnical News, 5, 43-44. 